\title{
The Assessments of Music Therapy for Dementia Based on the Cochrane Review
}

\author{
Makiko Abe ${ }^{a, b}$ Ken-ichi Tabei ${ }^{c}$ Masayuki Satoh ${ }^{b}$ \\ aDepartment of Community Mental Health \& Low, National Center of Neurology and Psychiatry, Tokyo, Japan; \\ ${ }^{b}$ Department of Dementia and Neuropsychology, Advanced Institute of Industrial Technology, Tokyo Metropolitan \\ Public University Corporation, Tokyo, Japan; 'School of Industrial Technology, Advanced Institute of Industrial \\ Technology, Tokyo Metropolitan Public University Corporation, Tokyo, Japan
}

\section{Keywords}

Music therapy · Dementia - Evaluation scale

\begin{abstract}
Background: Research on music therapy for dementia has taken a variety of measures and has been slow to consolidate evidence. Examining the outcomes that are currently being investigated and the measures that have been used can be useful for future research on music therapy for dementia. Objectives: This study used cited original papers from a review in the Cochrane Database of Systematic Reviews to determine if there are items that should be measured or scales that should be used in conducting research on music therapy for dementia. The rating scales used and the outcomes examined were extracted. Method: We used Dodd's criteria to identify (1) the outcome domains examined in music therapy for dementia, (2) the measures used, and (3) the measures capable of detecting significant intervention effects. Result: A search for reviews was conducted, and 7 systematic reviews (78 articles) were identified. Among them, 30 articles met the inclusion criteria. The 30 articles examined 18 of the 38 items in Dodd's outcome categories, while 20 items were not examined, and 78 different survey methods were used. The items most frequently surveyed in the studies were psychiatric outcomes, cognitive functioning, and global quality of life general outcomes. Conclusions: We
\end{abstract}

found that many studies investigated cognitive function, behavioral and psychological symptoms of dementia (BPSD), and quality of life; compared to BPSD, various types of rating scales were used for cognitive function. By standardizing the rating scales, we can contribute to the accumulation of evidence for music therapy for dementia.

(C) 2022 The Author(s)

Published by S. Karger AG, Basel

\section{Introduction}

The treatment of dementia involves a combination of pharmacological and nonpharmacological therapies. Nonpharmacological therapies may be prioritized, especially for behavioral and psychological symptoms of dementia (BPSD) $[1,2]$. However, the status of the recommended grade for implementation of nonpharmacological therapies in Japan, including music therapy for dementia, is weak, and the overall evidence is considered inconclusive. Despite various studies on the therapeutic effects of music therapy, conclusive evidence for its use in treating dementia has not been established.

Kelly et al. [3] collected more than 4,200 responses from approximately 1,500 participants on the question, "What should be investigated in future research on dementia"? and published the top 10 responses in rank or-
(C) 2022 The Author(s)

Published by S. Karger AG, Basel

This is an Open Access article licensed under the Creative Commons Attribution-NonCommercial-4.0 International License (CC BY-NC) (http://www.karger.com/Services/OpenAccessLicense), applicable to the online version of the article only. Usage and distribution for commercial purposes requires written permission.
Correspondence to:

Makiko Abe, makiko.t.abe@gmail.com 
der. "Establishing evidence for pharmacological and nonpharmacological therapies to manage BPSD" was ranked fourth, and establishing evidence for music therapy was found to be desired [3]. However, some studies on music therapy for dementia do not have sufficient data to support the conclusions discussed in the articles [4], making the issue of evidence and quality of research on music therapy for dementia an urgent matter to be addressed.

A core outcome set (COS) helps to establish evidence in clinical research. A COS is a consensus-derived, standardized, and parsimonious collection of outcomes to be reported at minimum in all studies of a particular condition ("what" to measure) [5-8]. A COS for music therapy for dementia would facilitate the aggregation of the effects of music therapy interventions for dementia, leading to the establishment of evidence. However, there is no COS for music therapy for dementia currently, and the outcomes have not been classified. If the researchers used different batteries to assess the intervention effects, we cannot compare the results between them, and it may prevent from establishing the evidence.

The present study examined the outcomes and measures investigated in music therapy for dementia, found in the Cochrane Database of Systematic Reviews (CDSR), as a preliminary step in the development of a COS. These outcomes and measures were categorized based on an outcome taxonomy created by Dodd et al. [9] that can be used in general medical clinical research. It consists of 38 items comprising mortality, physiological and clinical, impact on life, resource utilization, and adverse events. This is used in both clinical $[10,11]$ and basic research using animal experiments such as mice [12]. The collection of outcomes for the COS is essentially a systematic review in the CDSR. However, there were only a few reviews of music therapy for dementia in the CDSR; hence, we used the articles in the reviews, extracted the rating scales used, and the outcomes examined. Dodd's criteria were used to identify (1) outcome domains examined in music therapy for dementia, (2) measures used, and (3) scales able to detect significant intervention effects, to determine whether there were any items to be measured and any scales to be used in conducting research on music therapy for dementia.

\section{Materials and Methods}

The following words were used to search the CDSR: "dementia," "music," and "therapy," in studies registered on or before September 1,2020. The inclusion criteria were as follows: (1) articles reporting results of studies using music therapy, music intervention, or music stimulation, (2) articles were written in English, and
Table 1. The 30 articles examined 18 of the 38 items in Dodd's outcome categories

\begin{tabular}{lll}
\hline & Outcome domain & Studies, \\
& & $n$ \\
\hline Physiological/ & Cardiac outcomes & 4 \\
clinical & Endocrine outcomes & 1 \\
& Ear and labyrinth outcomes & 1 \\
& General outcomes & 24 \\
& Injury and poisoning outcomes & 1 \\
& Nervous system outcomes & 7 \\
& Psychiatric outcomes & 27 \\
& Skin and subcutaneous tissue & 1 \\
& $\quad$ outcomes & 1 \\
\hline Life impact & Vascular outcomes & 4 \\
& Physical functioning & 2 \\
& Role functioning & 5 \\
& Emotional functioning/wellbeing & 24 \\
& Cognitive functioning & 8 \\
& Global quality of life & 3 \\
& Perceived health status & 1 \\
& Delivery of care & 8 \\
\hline Resource use & Personal circumstances & 6 \\
\hline & Societal/carer burden & \\
\hline & & \\
& &
\end{tabular}

(3) the target disease was dementia. The exclusion criteria were as follows: (1) articles reporting results of a study that did not use music therapy, music intervention, or music stimulation; (2) articles written in languages other than English; and (3) the subject of the study was not dementia. Only articles that met the inclusion criteria were included in the study. The items and scales examined in each article were extracted. The extracted items and scales were classified according to Dodd et al.'s [9] outcome taxonomy. All authors participated in the exclusion of articles, extraction of items, scales examined, and assignment to Dodd's classification; decisions were made by consensus in cases of differences.

The following methods were used to conduct the analysis: (1) identifying the items examined by each research article, categorized according to Dodd et al.'s [9] criteria, and identifying the applicable and nonapplicable outcome domains and (2) frequency of use of the measures used in each outcome domain and frequency of detection of significant differences. It was approved by the Research Safety and Ethics Committee of the Advanced Institute of Industrial Technology (No. 19009).

\section{Results}

Seven reviews $[4,13-18]$ used 76 articles, and 30 met the inclusion criteria [19-48] (Table 1). The 30 articles examined 18 of the 38 items in Dodd's outcome categories, while 20 items were not examined, and 78 different survey methods were used. The items most frequently 


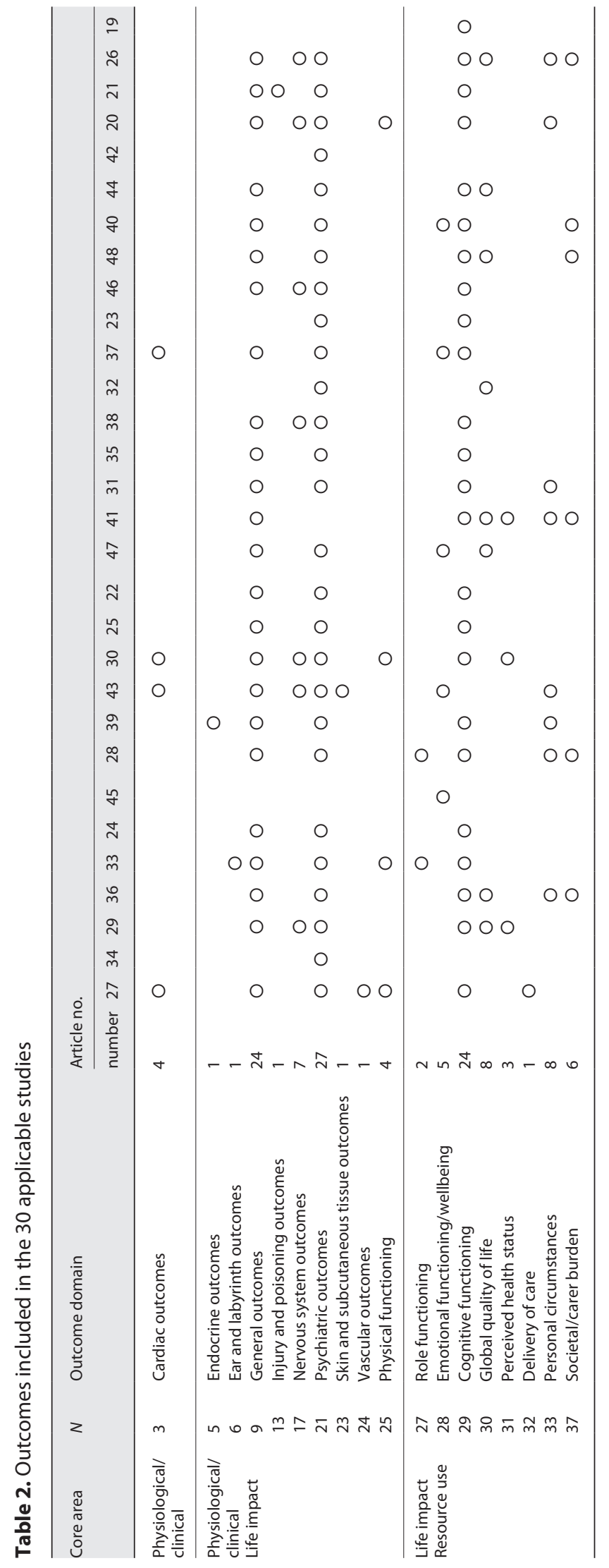

surveyed in the studies were psychiatric outcomes, cognitive functioning, and global quality of life general outcomes (Table 2). The frequency of use of the scales used in each outcome domain and the frequency of detecting significant differences are shown in Table 3.

\section{Discussion/Conclusion}

Many of the general outcomes were items examined as demographic data, and most studies examined age, gender, and education. Since this present review focused on studies of music therapy, music intervention, or music stimulation for dementia and not on subtypes of dementia (e.g., Alzheimer's disease [AD], dementia with Lewy bodies, and cerebrovascular dementia ), age, gender, and education were not included in the demographic data. In some studies, the classification of dementia type was also included in the demographic data.

The cognitive outcome revealed the use of a variety of measures of cognitive function in addition to general intelligence, including the Mini-Mental State Examination (MMSE). In dementia, multiple cognitive functions are impaired, reflecting the areas of functional decline in each disease. The main areas of cognitive decline include attention, executive function, memory, language, visuospatial cognition, action, and social cognition [49]. It was inferred that the wide range of symptoms expressed by patients of different subtypes of dementia led to the use of many scales to assess each of them. Särkämö et al. [41] used 9 cognitive function tests, the most used, in an attempt to assess overall cerebral function. While it is important to use scales according to the functions to be assessed, the burden on the target dementia patients must be considered. It is therefore necessary to reorganize the scales to assess the patients' conditions with the least possible number of assessment method.

The most frequently rated psychiatric outcome reflected the BPSD rating in dementia. According to previous reports, music therapy and other music interventions for dementia have been shown to improve BPSD, with effects on anxiety and depression reported by Ueda et al. [50] and those for agitation reported by Vink et al. $[38,42]$ and Lin et al. [31]. Many studies included in this review were concerned with BPSD, and many of them used the Cohen-Mansfield Agitation Inventory, a rating scale for agitation, although there were differences in the shortened or Chinese versions. Others used a rating scale for depression, a rating scale for anxiety, and a rating scale that can evaluate several BPSDs together. The Neuropsychiatric 
Table 3. The frequency of use of the scales used in each outcome domain and the frequency of detecting significant differences

\begin{tabular}{|c|c|c|c|c|c|}
\hline Outcome & Sub outcome & $\begin{array}{l}\text { Scale/ } \\
\text { survey } \\
\text { method, } n\end{array}$ & Scale/survey method & Pertinent & $\begin{array}{l}\text { Detections, } \\
n\end{array}$ \\
\hline \multirow[t]{3}{*}{ Cardiac outcomes } & HR and variability & 3 & $\mathrm{HR}$ & 2 & 1 \\
\hline & & & ECG Holter monitoring (HR variability) & 1 & 1 \\
\hline & Actual prevalence of heart disease & 1 & Actual prevalence of heart disease & 1 & \\
\hline Endocrine outcomes & Stress & 1 & Salivary cortisol & 1 & \\
\hline Ear and labyrinth outcomes & Hearing skill & 1 & $\begin{array}{l}\text { Hearing and perceptive-communicative } \\
\text { and relational skills }\end{array}$ & 1 & \\
\hline \multirow[t]{9}{*}{ General outcomes } & Characteristics & 70 & Age & 24 & \\
\hline & & & Sex & 24 & \\
\hline & & & Education & 13 & \\
\hline & & & Marital status & 5 & \\
\hline & & & Main medicines & 2 & \\
\hline & & & Most recent occupation & 1 & \\
\hline & & & Religion & 1 & \\
\hline & Musical skill & 3 & Music Preference Questionnaire & 2 & \\
\hline & & & Musical Expertise Questionnaire & 1 & \\
\hline Injury and poisoning outcomes & Pain & 1 & Pain & 1 & 1 \\
\hline Nervous system outcomes & Diagnosis & 6 & Type of dementia & 6 & \\
\hline \multirow[t]{9}{*}{ Psychiatric outcomes } & Global BPSD & 14 & NPI & 9 & 8 \\
\hline & & & BEHAVE-AD & 2 & 2 \\
\hline & & & Observance & 3 & 1 \\
\hline & Anxiety & 4 & RAID & 3 & 1 \\
\hline & & & Hamilton Anxiety Scale & 1 & 1 \\
\hline & Depression & 7 & GDS & 5 & 3 \\
\hline & & & CSDD & 2 & 2 \\
\hline & Agitation & 14 & CMAI & 13 & 7 \\
\hline & & & VDB & 1 & 1 \\
\hline $\begin{array}{l}\text { Skin and subcutaneous tissue } \\
\text { outcomes }\end{array}$ & Skin conductance & 1 & Skin conductance (Q sensor) & 1 & \\
\hline Vascular outcomes & Blood pressure & 1 & Blood pressure & 1 & \\
\hline \multirow[t]{4}{*}{ Physical functioning } & ADL & 3 & Index of Independence in ADL & 3 & 1 \\
\hline & IADL & 1 & IADL & 1 & \\
\hline & Physical functioning & 2 & Use of walker or wheelchair & 1 & \\
\hline & & & Lawton and Brody's PSMS & 1 & \\
\hline \multirow[t]{3}{*}{ Role functioning } & Recording during music therapy & 3 & GMP & 1 & 1 \\
\hline & & & SVAM or Music Therapy Activity Scale & 1 & 1 \\
\hline & & & $\begin{array}{l}\text { Participant Engagement Observation } \\
\text { Checklist }\end{array}$ & 1 & 1 \\
\hline \multirow{7}{*}{$\begin{array}{l}\text { Emotional functioning/ } \\
\text { wellbeing }\end{array}$} & Anxiety & 2 & STAI-A & 2 & 1 \\
\hline & Emotional facial expressions & 3 & Facial Action System Coding & 1 & 1 \\
\hline & & & Faces Scale & 1 & 1 \\
\hline & & & $\mathrm{EFE}$ & 1 & 1 \\
\hline & $\begin{array}{l}\text { Measure both positive and negative } \\
\text { affect }\end{array}$ & 1 & PANAS & 1 & 1 \\
\hline & Discourse content & 1 & Discourse content & 1 & 1 \\
\hline & Mood & 1 & $\begin{array}{l}\text { Recall, social interaction, and mood } \\
\text { questionnaire }\end{array}$ & 1 & 1 \\
\hline
\end{tabular}

The Assessments of Music Therapy for Dementia Based on the CDSR 
Table 3 (continued)

\begin{tabular}{|c|c|c|c|c|c|}
\hline Outcome & Sub outcome & $\begin{array}{l}\text { Scale/ } \\
\text { survey } \\
\text { method, } n\end{array}$ & Scale/survey method & Pertinent & $\begin{array}{l}\text { Detections, } \\
n\end{array}$ \\
\hline \multirow[t]{23}{*}{ Cognitive functioning } & \multirow[t]{8}{*}{ Multiple cognitive functions } & \multirow[t]{8}{*}{26} & MMSE & 19 & 3 \\
\hline & & & ADAS-cog & 2 & 1 \\
\hline & & & Severe Impairment Battery & 1 & 1 \\
\hline & & & BIMS & 1 & 1 \\
\hline & & & BCRS & 1 & \\
\hline & & & Short Portable Mental Status & 1 & \\
\hline & & & Questionnaire & & \\
\hline & & & $\begin{array}{l}\text { Consortium to Establish a Registry for } \\
\text { Alzheimer's Disease battery }\end{array}$ & 1 & \\
\hline & \multirow[t]{4}{*}{ Severity of dementia } & \multirow[t]{4}{*}{11} & $\begin{array}{l}\text { Clinical Developmental Stage of Dementia } \\
\text { (FAST) }\end{array}$ & 1 & 1 \\
\hline & & & CDR & 6 & \\
\hline & & & GDS & 2 & \\
\hline & & & Severity of dementia (no scale) & 2 & \\
\hline & \multirow[t]{4}{*}{ Memory function } & \multirow[t]{4}{*}{4} & MPI and MPD & 1 & 1 \\
\hline & & & WHO-UCLA AVLT & 1 & 1 \\
\hline & & & WMSR & 1 & \\
\hline & & & Forward and reverse digit-span exercise & 1 & \\
\hline & \multirow[t]{3}{*}{ Language function } & \multirow[t]{3}{*}{3} & Semantic verbal fluency test & 1 & 1 \\
\hline & & & Boston Naming Test & 1 & \\
\hline & & & Western Aphasia Battery & 1 & \\
\hline & \multirow[t]{3}{*}{ Frontal function } & \multirow[t]{3}{*}{3} & Attentional matrixes & 1 & 1 \\
\hline & & & Trail Making Test & 1 & \\
\hline & & & Frontal Assessment Battery & 1 & \\
\hline & Intellectual function & 1 & WAIS & 1 & \\
\hline \multirow[t]{6}{*}{ Global quality of life } & \multirow[t]{6}{*}{ QOL } & \multirow[t]{6}{*}{14} & Barthel Index & 3 & \\
\hline & & & QOL-AD & 2 & 2 \\
\hline & & & CBSQoL & 2 & 2 \\
\hline & & & DQOL & 2 & 2 \\
\hline & & & DCM & 1 & 1 \\
\hline & & & Alzheimer's Disease-Related Quality of Life & 1 & \\
\hline Perceived health status & Duration of disease & 1 & Duration of disease & 3 & \\
\hline Delivery of care & Assess the state of care & 1 & Assess the state of care & 1 & \\
\hline \multirow[t]{2}{*}{ Personal circumstances } & Length of stay & 6 & Length of stay at care facility & 6 & \\
\hline & Dyad partner & 2 & $\begin{array}{l}\text { Dyad partner (spouse/child/sibling or } \\
\text { other relative/nurse) }\end{array}$ & 1 & \\
\hline \multirow[t]{5}{*}{ Societal/carer burden } & \multirow[t]{2}{*}{ Care burden } & \multirow[t]{2}{*}{3} & NPI & 2 & \\
\hline & & & Zarit Burden Interview & 1 & \\
\hline & \multirow[t]{3}{*}{ Proxy level of care } & 1 & Staff proxy level & 1 & \\
\hline & & 1 & Level of care in facility & 1 & \\
\hline & & 1 & Global Health Questionnaire & 1 & \\
\hline
\end{tabular}

HR, heart rate; BEHAVE-AD, Behavior Pathology in Alzheimer's Disease Rating Scale; RAID, Rating Anxiety in Dementia Scale; GDS, Geriatric Depression Scale; CSDD, Cornell Scale Depression in Dementia; CMAI, Cohen-Mansfield Agitation Inventory; VDB, VERBALLY disruptive behaviors; ADL, Activities of Daily Living; IADL, Instrumental Activities of Daily Living; PSMS, Physical Self Maintenance Scale; GMP, Geriatric Music Therapy Profile; SVAM, Scala di valutazione dellattivita musicoterapeutica; STAI-A, State Trait Anxiety inventory for Adults; EFE, emotional facial expressions; PANAS, Positive and Negative Affect Schedule; ADAS-cog, Alzheimer's Disease Assessment Scale; BIMS, Brief Interview for Mental Status; BCRS, Brief Cognitive Rating Scale; CDR, Clinical Dementia Rating scale; GDS, Global Deterioration Scale; MPI and MPD, Immediate and Deferred Prose Memory test; WHO-UCLA AVLT, World Health Organization University of California-Los Angeles, Auditory Verbal Learning Test; WMSR, Wechsler Memory Scale III; WAIS, Wechsler Adult Intelligence Scale; QOL-AD, Quality of Life-Alzheimer's Disease; CBSQoL, Cornell Brown Scale Quality of Life; DQOL, Dementia Quality of Life questionnaire; DCM, Dementia Care Mapping. 
Inventory (NPI) evaluates the occurrence, frequency, and severity of BPSD, and there are various versions, such as that for clinicians and nursing homes. The NPI also assesses the burden of care for each item, and some studies have partially used the NPI to assess care burden. While many studies have assessed BPSD, the method of assessment has remained constant compared to that for other items. Moreover, the use of these rating scales in studies of music therapy and music intervention for dementia has been thought to be useful in accumulating evidence.

There is a wide variety of quality of life (QOL) scales for $\mathrm{AD}$, and the present review revealed that many scales have been used in traditional music therapy and music intervention research. QOL assessment scales follow Lowton's QOL model and have a variety of response formats, including those that require responses to caregivers [51]. Further, there are QOL scales for the elderly that are not limited to $\mathrm{AD}$ [52]. The QOL scale itself is under review, and it is anticipated that an optimal scale will be found in order to accumulate evidence for music therapy and music intervention in dementia.

Finally, 20 categories were not investigated in the articles included in the survey. The outcome classifications developed by Dodd et al. [9] are a classification table that can be applied in general clinical research, and some categories were not applicable to dementia (e.g., congenital, familial, and hereditary outcomes; pregnancy and perinatal outcomes). However, economic outcomes have been examined in several previous studies [53, 54], and in particular, music therapy for BPSD in dementia has been found to be more economical and more effective than pharmacotherapy. Importantly, while the studies reviewed were intervention studies, adverse events were not reported. Further, although singing was used in the intervention, respiratory outcomes were not assessed, suggesting that there are several issues that need to be clarified in future intervention studies using music therapy and music for dementia.

Consequently, we extracted articles used in a systematic review in CDSR. In a normal review study, it is desirable to extract and analyze the data according to the PRISMA guidelines, but the content of this study did not meet the PRISMA guidelines. Therefore, we decided to proceed with the study in an exploratory manner. This is a limitation of this study.

In conclusion, we investigated the effects of music therapy on dementia from articles used in a systematic review housed in the CDSR. As a result, we found that many studies investigated cognitive function, BPSD, and quality of life; compared to BPSD, various types of rating scales were used for cognitive function. By standardizing the rating scales, we can contribute to the accumulation of evidence for music therapy for dementia.

\section{Statement of Ethics}

This study protocol was reviewed and approved by Committee of the Advanced Institute of Industrial Technology, approval number 19009.

\section{Conflict of Interest Statement}

The authors have no conflicts of interest to declare.

\section{Funding Sources}

This study was supported by JSPS KAKENHI Grant-in-Aid for Scientific Research (B) (Grant No.: 20H04303), Grant-in-Aid for Scientific Research (C) (Grant No.: 21K12194), and Grant-in-Aid for Young Scientist (B) (Grant No.: 17K17811).

\section{Author Contributions}

Conception and design of the experiments were contributed by M.A. Research studies were conducted by M.A., K.T., and M.S. Data analysis was contributed by M.A., K.T., and M.S. Writing of the paper was contributed by M.A. Supervision and interpretation of the data were contributed by K.T. and M.S. All authors read and approved the final version of the paper.

References

1 Kales HC, Gitlin LN, Lyketsos CG. Management of neuropsychiatric symptoms of dementia in clinical settings: recommendations from a multidisciplinary expert panel. J Am Geriatr Soc. 2014 Apr;62(4):762-9.

2 Gauthier S, Cummings J, Ballard C, Brodaty $\mathrm{H}$, Grossberg G, Robert P, et al. Management of behavioral problems in Alzheimer's disease. Int Psychogeriatr. 2010 May;22(3):346-72.

3 Kelly S, Lafortune L, Hart N, Cowan K, Fenton M, Brayne C. Dementia priority setting partnership with the James Lind Alliance: using patient and public involvement and the evidence base to inform the research agenda. Age Ageing. 2015 Nov;44(6):985-93.

4 van der Steen JT, Smaling HJ, van der Wouden JC, Bruinsma MS, Scholten RJ, Vink AC. Music-based therapeutic interventions for people with dementia. Cochrane Database Syst Rev. 2018 Jul 23;7(7):Cd003477.

5 Clarke M. Standardising outcomes for clinical trials and systematic reviews. Trials. $2007 \mathrm{Nov}$ $26 ; 8: 39$.
The Assessments of Music Therapy for Dementia Based on the CDSR
Dement Geriatr Cogn Disord Extra 2022;12:6-13 DOI: $10.1159 / 000521231$ 
6 Sinha IP, Smyth RL, Williamson PR. Using the Delphi technique to determine which outcomes to measure in clinical trials: recommendations for the future based on a systematic review of existing studies. PLoS Med. 2011 Jan 25;8(1):e1000393.

7 Williamson PR, Altman DG, Blazeby JM, Clarke M, Devane D, Gargon E, et al. Developing core outcome sets for clinical trials: issues to consider. Trials. 2012 Aug 6;13:132.

8 Williamson P, Altman D, Blazeby J, Clarke M, Gargon E. Driving up the quality and relevance of research through the use of agreed core outcomes. J Health Serv Res Policy. 2012 Jan; 17(1):1-2

9 Dodd S, Clarke M, Becker L, Mavergames C, Fish R, Williamson PR. A taxonomy has been developed for outcomes in medical research to help improve knowledge discovery. J Clin Epidemiol. 2018 Apr;96:84-92.

10 Mathioudakis AG, Fally M, Hashad R, Kouta A, Hadi AS, Knight SB, et al. Outcomes evaluated in controlled clinical trials on the management of COVID-19: a methodological systematic review. Life. 2020 Dec 15;10(12):350.

11 Katiri R, Hall DA, Killan CF, Smith S, Prayuenyong P, Kitterick PT. Systematic review of outcome domains and instruments used in designs of clinical trials for interventions that seek to restore bilateral and binaural hearing in adults with unilateral severe to profound sensorineural hearing loss ("single-sided deafness”). Trials. 2021 Mar 20; 22(1):220.

12 Harman NL, Sanz-Moreno A, Papoutsopoulou S, Lloyd KA, Ameen-Ali KE, Macleod M, et al. Can harmonisation of outcomes bridge the translation gap for pre-clinical research? A systematic review of outcomes measured in mouse models of type 2 diabetes. J Transl Med. 2020 Dec 9;18(1):468.

13 Chung JC, Lai CK, Chung PM, French HP Snoezelen for dementia. Cochrane Database Syst Rev. 2002;(4):Cd003152.

14 Hermans DG, Htay UH, McShane R. Nonpharmacological interventions for wandering of people with dementia in the domestic setting. Cochrane Database Syst Rev. 2007 Jan 24;2007(1):Cd005994.

15 Woods B, Aguirre E, Spector AE, Orrell M. Cognitive stimulation to improve cognitive functioning in people with dementia. Cochrane Database Syst Rev. 2012 Feb 15;(2): Cd005562.

16 Woods B, O'Philbin L, Farrell EM, Spector AE, Orrell M. Reminiscence therapy for dementia. Cochrane Database Syst Rev. 2018 Mar 1;3(3):Cd001120.

17 Abraha I, Rimland JM, Lozano-Montoya I, Dell'Aquila G, Vélez-Díaz-Pallarés M, Trotta FM, et al. Simulated presence therapy for dementia. Cochrane Database Syst Rev. 2020 Apr 20;4(4):Cd011882.

18 Orgeta V, McDonald KR, Poliakoff E, Hindle JV, Clare L, Leroi I. Cognitive training interventions for dementia and mild cognitive impairment in Parkinson's disease. Cochrane
Database Syst Rev. 2020 Feb 26;2(2): Cd011961.

19 Lord TR, Garner JE. Effects of music on Alzheimer patients. Percept Mot Skills. 1993 Apr; 76(2):451-5.

20 Cohen-Mansfield J, Werner P. Management of verbally disruptive behaviors in nursing home residents. J Gerontol A Biol Sci Med Sci. 1997 Nov;52(6):M369-77.

21 Clark ME, Lipe AW, Bilbrey M. Use of music to decrease aggressive behaviors in people with dementia. J Gerontol Nurs. 1998 Jul; 24(7):10-7.

22 Requena C, López Ibor MI, Maestú F, Campo $P$, López Ibor JJ, Ortiz T. Effects of cholinergic drugs and cognitive training on dementia. Dement Geriatr Cogn Disord. 2004;18(1):50-

23 Svansdottir HB, Snaedal J. Music therapy in moderate and severe dementia of Alzheimer's type: a case-control study. Int Psychogeriatr. 2006 Dec;18(4):613-21.

24 Garland K, Beer E, Eppingstall B, O'Connor DW. A comparison of two treatments of agitated behavior in nursing home residents with dementia: simulated family presence and preferred music. Am J Geriatr Psychiatry. 2007 Jun;15(6):514-21.

25 Guétin S, Portet F, Picot MC, Pommié C, Messaoudi M, Djabelkir L, et al. Effect of music therapy on anxiety and depression in patients with Alzheimer's type dementia: randomised, controlled study. Dement Geriatr Cogn Disord. 2009;28(1):36-46.

26 Cooke M, Moyle W, Shum D, Harrison S, Murfield J. A randomized controlled trial exploring the effect of music on quality of life and depression in older people with dementia. J Health Psychol. 2010 Jul;15(5):765-76.

27 Cooke ML, Moyle W, Shum DH, Harrison SD, Murfield JE. A randomized controlled trial exploring the effect of music on agitated behaviours and anxiety in older people with dementia. Aging Ment Health. 2010 Nov;14(8): 905-16.

28 Harrison S, Cooke M, Moyle W, Shum D, Murfield JE. Development of a music intervention protocol and its effect on participant engagement: experiences from a randomised controlled trial with older people with dementia. Arts Health. 2010;2(2):125-39.

29 Raglio A, Bellelli G, Traficante D, Gianotti M, Ubezio MC, Gentile S, et al. Efficacy of music therapy treatment based on cycles of sessions: a randomised controlled trial. Aging Ment Health. 2010 Nov; 14(8):900-4

30 Raglio A, Oasi O, Gianotti M, Manzoni V, Bolis S, Ubezio MC, et al. Effects of music therapy on psychological symptoms and heart rate variability in patients with dementia. A pilot study. Curr Aging Sci. 2010 Dec; 3(3):242-6.

31 Lin Y, Chu H, Yang CY, Chen CH, Chen SG, Chang HJ, et al. Effectiveness of group music intervention against agitated behavior in elderly persons with dementia. Int J Geriatr Psychiatry. 2011 Jul;26(7):670-8.
32 Murfield J, Cooke M, Moyle W, Shum D, Harrison S. Conducting randomized controlled trials with older people with dementia in long-term care: challenges and lessons learnt. Int J Nurs Pract. 2011 Feb;17(1):52-9.

33 Ceccato E, Vigato G, Bonetto C, Bevilacqua A, Pizziolo P, Crociani S, et al. STAM protocol in dementia: a multicenter, single-blind, randomized, and controlled trial. Am J Alzheimers Dis Other Demen. 2012 Aug;27(5):301-10.

34 Raglio A, Bellelli G, Traficante D, Gianotti M, Ubezio MC, Gentile S, et al. Addendum to "Efficacy of music therapy treatment based on cycles of sessions: a randomised controlled trial" (Raglio et al., 2010). Aging Ment Health. 2012;16(2):265-7.

35 Sung HC, Lee WL, Li TL, Watson R. A group music intervention using percussion instruments with familiar music to reduce anxiety and agitation of institutionalized older adults with dementia. Int J Geriatr Psychiatry. 2012 Jun;27(6):621-7.

36 Ridder HM, Stige B, Qvale LG, Gold C. Individual music therapy for agitation in dementia: an exploratory randomized controlled trial. Aging Ment Health. 2013;17(6):667-78.

37 Sakamoto M, Ando H, Tsutou A. Comparing the effects of different individualized music interventions for elderly individuals with severe dementia. Int Psychogeriatr. 2013 May; 25(5):775-84.

38 Vink AC, Zuidersma $\mathrm{M}$, Boersma $\mathrm{F}$, de Jonge P, Zuidema SU, Slaets JP. The effect of music therapy compared with general recreational activities in reducing agitation in people with dementia: a randomised controlled trial. Int $J$ Geriatr Psychiatry. 2013 Oct;28(10):1031-8.

$39 \mathrm{Chu} \mathrm{H}$, Yang CY, Lin Y, Ou KL, Lee TY, O'Brien AP, et al. The impact of group music therapy on depression and cognition in elderly persons with dementia: a randomized controlled study. Biol Res Nurs. 2014 Apr;16(2): 209-17.

40 Narme P, Clément S, Ehrlé N, Schiaratura L, Vachez S, Courtaigne B, et al. Efficacy of musical interventions in dementia: evidence from a randomized controlled trial. J Alzheimers Dis. 2014;38(2):359-69.

41 Särkämö T, Tervaniemi M, Laitinen S, Numminen A, Kurki M, Johnson JK, et al. Cognitive, emotional, and social benefits of regular musical activities in early dementia: randomized controlled study. Gerontologist. 2014 Aug;54(4):634-50.

42 Vink AC, Zuidersma M, Boersma F, de Jonge $P$, Zuidema SU, Slaets JP. Effect of music therapy versus recreational activities on neuropsychiatric symptoms in elderly adults with dementia: an exploratory randomized controlled trial. J Am Geriatr Soc. 2014 Feb;62(2): 392-3.

43 Hsu MH, Flowerdew R, Parker M, Fachner J, Odell-Miller H. Individual music therapy for managing neuropsychiatric symptoms for people with dementia and their carers: a cluster randomised controlled feasibility study. BMC Geriatr. 2015 Jul 18;15:84. 
44 Raglio A, Bellandi D, Baiardi P, Gianotti M, Ubezio MC, Zanacchi E, et al. Effect of active music therapy and individualized listening to music on dementia: a multicenter randomized controlled trial. J Am Geriatr Soc. 2015 Aug;63(8):1534-9.

45 Samson S, Clément S, Narme P, Schiaratura L, Ehrlé N. Efficacy of musical interventions in dementia: methodological requirements of nonpharmacological trials. Ann N Y Acad Sci. 2015 Mar;1337:249-55.

46 Thornley J, Hirjee H, Vasudev A. Music therapy in patients with dementia and behavioral disturbance on an inpatient psychiatry unit: results from a pilot randomized controlled study. Int Psychogeriatr. 2016 May;28(5): 869-71.
47 Cho HK. The effects of music therapy-singing group on quality of life and affect of persons with dementia: a randomized controlled trial. Front Med. 2018;5:279.

48 Lyu J, Zhang J, Mu H, Li W, Champ M, Xiong $\mathrm{Q}$, et al. The effects of music therapy on cognition, psychiatric symptoms, and activities of daily living in patients with Alzheimer's disease. J Alzheimers Dis. 2018;64(4):1347-58.

49 Sachdev PS, Blacker D, Blazer DG, Ganguli $M$, Jeste DV, Paulsen JS, et al. Classifying neurocognitive disorders: the DSM-5 approach. Nat Rev Neurol. 2014 Nov;10(11):634-42.

50 Ueda T, Suzukamo Y, Sato M, Izumi S. Effects of music therapy on behavioral and psychological symptoms of dementia: a systematic review and meta-analysis. Ageing Res Rev. 2013 Mar; 12(2):628-41.

51 Ready RE, Ott BR. Quality of life measures for dementia. Health Qual Life Outcomes. 2003 Apr 23;1:11.
52 Bowling A, Stenner P. Which measure of quality of life performs best in older age? A comparison of the OPQOL, CASP-19 and WHOQOL-OLD. J Epidemiol Community Health. 2011 Mar;65(3):273-80.

53 Bellelli G, Raglio A, Trabucchi M. Music interventions against agitated behaviour in elderly persons with dementia: a cost-effective perspective. Int J Geriatr Psychiatry. 2012 Mar;27(3):327. author reply 328.

54 Livingston G, Kelly L, Lewis-Holmes E, Baio G, Morris S, Patel N, et al. A systematic review of the clinical effectiveness and cost-effectiveness of sensory, psychological and behavioural interventions for managing agitation in older adults with dementia. Health Technol Assess. 2014 Jun;18(39):1-226, v-vi.
The Assessments of Music Therapy for Dementia Based on the CDSR 